\title{
Comparison of Orthodontic Treatment Duration Among Extraction Versus Non Extraction Therapies
}

\author{
Dr Dashrath Kafle,' Dr Rajeev Kumar Mishra, ${ }^{2}$ Dr Ravi Kumar Mahto, ${ }^{2}$ Dr Sanjeev Luintel,3 \\ Dr Suja Shrestha, ${ }^{4}$ Dr Samikshya Sangroula ${ }^{3}$
}

\author{
'Associate Professor \& Head, ${ }^{2}$ Assistant Professor, 3Resident, 4Lecturer \\ Department of Orthodontics, Kathmandu University School of Medical Sciences
}

Correspondence: Dr Dashrath Kafle; Email: dashratho7@yahoo.com

ABSTRACT

Introduction: Orthodontic treatment is usually perceived as a lengthy treatment as average treatment time usually last more than a year and may go up to even five years. So, in orthodontic practice the optimum treatment result with minimal treatment time should be the goal of clinicians. Treatment duration varies based on different clinico-environmental factors.

Materials \& Method: Total 200 cases were randomly selected from the archives of debonded treatmnent records from the department of orthodontics, Dhulikhel Hospital, Kathmandu University Teaching Hospital. Out of the 200 records, 103 records were fit for the study based on previously set inclusion and exclusion criteria. The selected cases were divided into three different groups: extraction $n=28$ (extraction of 4 premolars), partial extraction= 19, (extraction of 1-3 teeth) and non-extraction $n=56$. Furthermore, the cases were also divided into Class I, II and III malocclusion patterns. After doing the test of normality, descriptive statistics, independent samples t test and ANOVA test were performed to compare the treatment duration with respect to gender, malocclusion pattern and treatment modalities.

Result: Out of the 103 selected cases, maximum number of cases were of Class I(60) followed by Class II(37) and Class III(6). There was no statistical significance on treatment duration among male and female subjects $(p=0.933)$ as well as among different malocclusion pattern $(p=0.255)$. On the contrary, there was statistical difference on treatment duration among non extraction, partial extraction and extraction groups $(p=0.0004)$. The average treatment duration for non extraction, partial extraction and extraction group were 22,28 and 29 months respectively.

Conclusion: Orthodontic treatment duration is shorter for therapies done by non extraction than extraction. The average treatment duration for non extraction and extraction therapy is 22 and 29 months respectively. The treatment duration is not affected by gender and type of malocclusion.

Keywords: : Extraction, Malocclusion, Non extraction, Orthodontic, Treatment duration.

\section{INTRODUCTION}

Orthodontic treatment is usually perceived as a lengthy and painful procedure by lay people. There is no denial that orthodontic treatment should have optimum end result in shortest possible duration. However the treatment duration depends upon several factors like extraction versus non extraction, age of the patient, type and severity of malocclusion, skeletal versus dental problem, technique applied, experience of the patient, setting of the treatment centre as well as involvement of surgical versus non surgical procedures. ${ }^{1-7}$ The treatment duration might even be affected by the compliance of the patient, socioeconomic factors, amount of bonding failure as well as adherence to the appointment schedule. ${ }^{7.8}$
According to the recently published systemic review, routine comprehensive orthodontic treatment duration involving fixed orthodontic therapy range from 14-33 months with the average duration of 19 months. 9 However some other studies have mentioned about the duration of 18-24 months on average with some treatment lasting even 48 months.9.10 A recently conducted randomized control trial has concluded that even though bracket slot does not affect the treatment duration but the missed appointment and emergencies, age of the patient and multi operator treatment increases the treatment duration." Every orthodontist should aim at finishing the case in shorter duration. The longer treatment duration is detrimental for the reputation of the practice and treating doctor. In term of practice management, longer than expected 
treatment duration is taken as a loss. The duration of the treatment is the commonly asked question by patient parties before starting treatment. The most prevalent malocclusion globally is Class I followed by Class $11 .{ }^{12}$ The management of both the malocclusion might need extraction in some situation. Number of studies have been done to evaluate the pros and cons of extraction versus non extraction orthodontics however there is still a dilemma on deciding which therapy is better in term of final outcome and treatment duration. ${ }^{13-15}$ The serial extraction in mixed dentition followed by orthodontic therapy reduces the treatment time compared to comprehensive orthodontic treatment with four premolar extraction. ${ }^{16}$ There are number of adjunct therapies which are targeted to reduce the duration of the orthodontic treatment such as low level laser therapy, application of vibration, corticotomies and corticopuncture etc however their effectiveness is always questionable. ${ }^{17-19}$ The prolonged treatment duration is associated with external apical root resorption, plaque induced problems including dental caries, white spot lesion, periodontal breakdown and patient burn out. ${ }^{20-22}$ Despite all these multi factorial causes for treatment duration and multiple studies, there is a strong need to address the duration of orthodontic treatment duration done in Nepalese population as cultural, psychosocial and socioeconomic condition play a role on treatment duration. Hence the aim of this study is to find out the average orthodontic treatment time for extraction and non extraction orthodontic therapy as well as to find out whether treatment duration in both the modalities is same or not.

\section{MATERIALS AND METHOD}

This was the restrospective observational study in which total 200 cases were randomly selected from the archives of debonded treatmnent records from the department of orthodontics, Dhulikhel Hospital, Kathmandu University teaching hospital after obtaining approval from Institutional review committee of Kathmandu University School of Medical Sciences. Out of the 200 records, 103 records were fit for the study based on previously set inclusion and exclusion criteria. Patients who underwent comprehensive orthodontic therapy in permanent dentition and both the arches with good records were included in the study whereas cases treated for impacted teeth, incomplete records, retreatment, craniofacial anomalies and developing skeletal malocclusion were excluded from the study. The selected cases were divided into three different groups: extraction $n=28$ (extraction of 4 premolars), partial extraction $=19$, (extraction of 1-3 teeth) and non-extraction $n=56$. Furthermore the cases were also divided into Class I, II and III malocclusion pattern. As Class III cases were very low in number, they were not analysed further in this study.

After doing the test of normality, descriptive statistics, independent samples t test and ANOVA test were performed to compare the treatment duration with respect to gender, malocclusion pattern and treatment modalities.

\section{RESULT}

The descriptive statistics on distribution of gender and malocclusion pattern is shown in table I and II. There is no statistical difference on treatment duration among male and female subjects as well as class I and Class II malocclusion types.

The descriptive statistics and comparison of treatment duration among different treatment modalities are explained in Table III and IV. There is significant difference on treatment duration among non extraction, partial extraction and extraction group. The mean duration of treatment with non extraction therapy is 22 months followed by partial extraction and extraction therapies which are 28 and 29 months respectively. Further post hoc analysis shows that treatment duration for

Table 1: Duration of orthodontic treatment among different malocclusion

\begin{tabular}{|c|c|c|c|c|}
\hline Malocclusion & N & Mean & S.D. & p-value \\
\hline Class I & 60 & 24.95 & 8.57 & \multirow{2}{*}{0.255} \\
\hline Class II & 37 & 26.03 & 7.08 & \\
\hline Class III & 6 & - & - & \\
\hline
\end{tabular}

Table 2: Duration of orthodontic treatment among gender

\begin{tabular}{|c|c|c|c|c|}
\hline Gender & N & Mean & S.D. & p-value \\
\hline Male & 32 & 25.25 & 7.21 & \multirow{2}{*}{0.933} \\
\hline Female & 71 & 25.39 & 8.40 & \\
\hline
\end{tabular}


Table 3: Duration of orthodontic treatment among different treatment modalities

\begin{tabular}{|c|c|c|c|c|}
\hline Treatment modality & N & Mean & S.D. & p-value \\
\hline Non-extraction & 56 & 22.59 & 7.08 & $0.0004^{* *}$ \\
\hline Partial-extraction & 19 & 27.95 & 8.79 & \\
\hline 4 premolars-extraction & 28 & 29.10 & 7.34 & \\
\hline
\end{tabular}

Table 4: Duration of orthodontic treatment among different treatment modalities (POST-HOC TEST)

\begin{tabular}{|c|l|c|c|}
\hline \multicolumn{2}{|c|}{ Treatment modality } & Mean difference & p-value \\
\hline \multirow{2}{*}{ Non-extraction } & Partial extraction & -5.36 & $0.022^{*}$ \\
\cline { 2 - 4 } & 4 premolars extraction & -6.52 & $0.01^{*}$ \\
\hline \multirow{2}{*}{ Partial extraction } & Non-extraction & 5.36 & $0.022^{*}$ \\
\cline { 2 - 4 } & 4 premolars extraction & -1.16 & 0.861 \\
\hline \multirow{2}{*}{4 premolars extraction } & Non-extraction & 6.52 & $0.01^{*}$ \\
\cline { 2 - 4 } & Partial extraction & 1.16 & 0.861 \\
\hline
\end{tabular}

* Significant **Highly significant

non extraction is significantly different in comparison to both the extraction groups. However, there is no significant difference on treatment duration among partial extraction and extraction group.

\section{DISCUSSION}

The duration of orthodontic treatment is always a crucial factor. It is beneficial to complete the treatment duration in shortest possible time which is not always possible. The duration of comprehensive orthodontic treatment is multifactorial. The average treatment duration in our study is 26 months, shortest for non extraction therapy, 22 months and longest for extraction therapy, 29 months. The previous study done in Nepal has shown the average treatment time of 28 months and 30 months for adults and adolescents respectively however they have not divided the duration on the basis of extraction versus non extraction and the study was based on private practice. The study done by Fink et al has shown the average treatment duration of orthodontic treatment of 23 months ranging from 19 to 27 months which is less than that of our study. ${ }^{8} \mathrm{~A}$ recent systematic review has also shown the average treatment duration of fixed orthodontic therapy is 18 months which is almost 8 months less than that of our study. "The duration of orthodontic treatment depends upon the severity and type of malocclusion, appointment adherence and compliance of the patient, treatment mechanics applied etc. ${ }^{1,223}$ The socioeconomic and psychological factors are also found to be associated with orthodontic treatment duration. ${ }^{24}$ Higher maternal involvement in treatment is found to have shortened the treatment duration. ${ }^{24}$ According to our studty, non extraction treatment takes relatively shorter duration than that of extraction which is similar to other studies as well. ${ }^{7,25}$ The treatment duration among partial teeth extraction versus all four premolar extractions was not significantly different which is contradictory to the finding by Janson et al. ${ }^{26}$ In our study partial extraction group consisted 1-3 premolar extraction cases where as in the study of Jason et all, they had strict criteria for partial extraction that was Class II cases with only 2 premolar extraction. The future of orthodontic lies on reducing the treatment time without compromising the result. For that number of novel devices and methods such as corticotomies, laser therapy, bracket modification as well as application of vibration have been proposed and tried but the effectiveness of these methods are still controversial.6,18,19,27 Despite all the factors, patient's inherent biological response to force, type and severity of malocclusion and compliance of the patient should also be considered seriously.

\section{CONCLUSION}

Orthodontic treatment duration is shorter for therapies done by non extraction than extraction. The average treatment duration for non extraction and extraction therapy is 22 and 29 months respectively. The treatment duration is not affected by gender and type of malocclusion. 


\section{REFERENCES}

1. Jarvinen S, Widstrom E, Raitio M. Factors affecting the duration of orthodontic treatment in children. A retrospective study. Swedish dental journal. 2004;28(2):93-100.

2. Mavreas D, Athanasiou AE. Factors affecting the duration of orthodontic treatment: a systematic review. European journal of orthodontics. 2008;30(4):386-95.

3. Robb SI, Sadowsky C, Schneider BJ, BeGole EA. Effectiveness and duration of orthodontic treatment in adults and adolescents. American journal of orthodontics and dentofacial orthopedics. 1998;114(4):383-6.

4. Seehra J, Al-Ali A, Pandis N, Cobourne MT. Space closure versus space opening for bilateral absent upper lateral incisors: what is the duration of orthodontic treatment? European journal of orthodontics. 2019.

5. Taylor PJ, Kerr WJ, McColl JH. Factors associated with the standard and duration of orthodontic treatment. British journal of orthodontics. 1996;23(4):335-41.

6. Beckwith FR, Ackerman RJ, Jr., Cobb CM, Tira DE. An evaluation of factors affecting duration of orthodontic treatment. American journal of orthodontics and dentofacial orthopedics. 1999;115(4):439-47.

7. Fisher MA, Wenger RM, Hans MG. Pretreatment characteristics associated with orthodontic treatment duration. American journal of orthodontics and dentofacial orthopedics. 2010;137(2):178-86.

8. Fink DF, Smith RJ. The duration of orthodontic treatment. American journal of orthodontics and dentofacial orthopedics. 1992; 102(1):45-51.

9. Tsichlaki A, Chin SY, Pandis N, Fleming PS. How long does treatment with fixed orthodontic appliances last? A systematic review. American journal of orthodontics and dentofacial orthopedics . 2016;149(3):308-18.

10. Richmond S, Andrews M, Roberts CT. The provision of orthodontic care in the general dental services of England and Wales: extraction patterns, treatment duration, appliance types and standards. British journal of orthodontics. 1993;20(4):345-50.

11. Yassir YA, El-Angbawi AM, Mclntyre GT, Revie GF, Bearn DR. A randomized clinical trial of the effectiveness of 0.018 -inch and 0.022-inch slot orthodontic bracket systems: part 1-duration of treatment. European journal of orthodontics. 2019;41 (2):133-42.

12. Alhammadi MS, Halboub E, Fayed MS, Labib A, El-Saaidi C. Global distribution of malocclusion traits: A systematic review. Dental press journal of orthodontics. 2018;23(6):40 el- e10.

13. Verma SL, Sharma VP, Tandon P, Singh GP, Sachan K. Comparison of esthetic outcome after extraction or non-extraction orthodontic treatment in class II division 1 malocclusion patients. Contemporary clinical dentistry. 2013;4(2):206-12.

14. Tauheed S, Shaikh A, Fida M. Microaesthetics of The Smile: Extraction vs. Non-extraction. Journal of the College of Physicians and Surgeons--Pakistan : JCPSP. 2012;22(4):230-4

15. Liu Y, Huang W, XU TM. [Long-term changes of hard-tissue in borderline cases with extraction vs. non-extraction treatment]. 2008;40(6):633-8.

16. Wagner M, Berg R. Serial extraction or premolar extraction in the permanent dentition? Comparison of duration and outcome of orthodontic treatment. Journal of orofacial orthopedics = Fortschritte der Kieferorthopadie. 2000;61 (3):207-16.

17. Lyu C, Zhang L, Zou S. The effectiveness of supplemental vibrational force on enhancing orthodontic treatment. A systematic review. European journal of orthodontics. 2019;41(5):502-12.

18. DiBiase AT, Woodhouse NR, Papageorgiou SN, Johnson N, Slipper C, Grant J, et al. Effects of supplemental vibrational force on space closure, treatment duration, and occlusal outcome: A multicenter randomized clinical trial. American journal of orthodontics and dentofacial orthopedics . 2018;153(4):469-80 e4.

19. Fleming PS, Fedorowicz Z, Johal A, El-Angbawi A, Pandis N. Surgical adjunctive procedures for accelerating orthodontic treatment. The Cochrane database of systematic reviews. 2015(6):CD010572.

20. Parrish LD, Roberts WE, Maupome G, Stewart KT, Bandy RW, Kula KS. The relationship between the ABO discrepancy index and treatment duration in a graduate orthodontic clinic. The Angle orthodontist. 2011;81(2):192-7.

21. Pinto AS, Alves LS, Maltz M, Susin C, Zenkner JEA. Does the Duration of Fixed Orthodontic Treatment Affect Caries Activity among Adolescents and Young Adults? Caries research. 2018;52(6):463-7.

22. Pinto AS, Alves LS, Zenkner J, Zanatta FB, Maltz M. Gingival enlargement in orthodontic patients: Effect of treatment duration. American journal of orthodontics and dentofacial orthopedics.2017;152(4):477-82.

23. Grewe JM, Hermanson PC. Influence of severity of malocclusion on the duration of orthodontic treatment. American journal of orthodontics. 1973;63(5):533-6.

24. Nakhleh K, Joury E, Dean R, Marcenes W, Johal A. Can socioeconomic and psychosocial factors predict the duration of orthodontic treatment? European journal of orthodontics. 2019.

25. Vig PS, Weintraub JA, Brown C, Kowalski CJ. The duration of orthodontic treatment with and without extractions: a pilot study of five selected practices. American journal of orthodontics and dentofacial orthopedics. 1990;97(1):45-51.

26. Janson G, Maria FR, Barros SE, Freitas MR, Henriques JF. Orthodontic treatment time in 2- and 4-premolar-extraction protocols. American journal of orthodontics and dentofacial orthopedics . 2006;129(5):666-71.

27. DiBiase AT, Nasr IH, Scott P, Cobourne MT. Duration of treatment and occlusal outcome using Damon3 self-ligated and conventional orthodontic bracket systems in extraction patients: a prospective randomized clinical trial. American journal of orthodontics and dentofacial orthopedics. 2011;139(2):e111-6. 